\title{
Lung function predicts lung cancer
}

\section{To the Editors:}

We read with great interest the recent article by CALABRO et al. [1] showing the close relationship between obstructive lung disease and lung cancer. In particular, we are interested in their suggestion that spirometry might play a very useful role in improving patient selection for targeted lung cancer screening.

Recently, we and others have shown that between 50 and $80 \%$ of patients diagnosed with lung cancer had pre-existing chronic obstructive pulmonary disease (COPD) [2-4] consistent with the findings of CALABRO et al. [1]. In our series of 446 lung cancer patients, we reported that $60-65 \%$ had prebronchodilator Global Initiative for Obstructive Lung Disease (GOLD) 1+ spirometric criteria for COPD [2] consistent with other published studies [3, 4]. This compared with a prevalence of only $15 \%$ in a randomly selected population of smokers matched for pack-yrs, sex, ethnicity and smoking exposure [2]. This suggests that the association between COPD and lung cancer is strongly independent of smoking exposure dose. Indeed, the risk of lung cancer conferred by a reduced forced expiratory volume in $1 \mathrm{~s}$ (FEV1) has been shown to be greater than that conferred by smoking dose (pack-yrs) [5]. When chest CT scan evidence of emphysema is included in the COPD (spirometric) criteria, the proportion of those with lung cancer showing signs of airway disease (small airways disease and/or emphysema) may even be higher than $80 \%$ [3]. Of interest, the study by CALABRO et al. [1] confirmed that even mild reductions in FEV1 ( $<90 \%$ predicted) are associated with lung cancer. In our series of nonscreened lung cancer cases [2], $80 \%$ had $\mathrm{FEV} 1<90 \%$ pred (unpublished data).

We have previously suggested that reduced FEV1 is a biomarker of susceptibility to smoking for both COPD and lung cancer [6]. Here we differ with the views of CALABRO et al. [1] who consider FEV1 to be a surrogate marker of exposure to carcinogens from smoking. Although smoking exposure is an important pre-requisite for most lung cancer, the contribution of smoking dose to the variance in FEV1 is modest and much less than that from genetic factors [7-9]. This would accord with data from epidemiological studies of chronic heavy smokers where the distribution of FEV1 is bi- or tri-modal rather than unimodal as it is in light and neversmokers [6]. In combination, these observations lead us to suggest that FEV1 is a very useful marker of "susceptibility" rather than exposure. This susceptibility of the lungs to smoking is probably due to the combined effects of exaggerated inflammation and/or aberrant repair [10]. The former being supported by the close correlation between elevated inflammatory markers (e.g. C-reactive protein or interleukin-6) and FEV1 decline in prospective studies [10].

The basis of the COPD-lung cancer association may be due to overlapping pathogenetic pathways, where exaggerated inflammation and/or lung remodelling leads to COPD (with release of matrix metalloproteinases and growth factors) and subsequent malignant transformation through epithelial mesenchymal transition [10]. Recent genome-wide association studies show that some of the genes implicated in lung cancer are also implicated in COPD [11]. Specifically, we and others reported in 2008 that the chromosome 15q25 locus, initially associated with lung cancer, is also associated with COPD [12]. One important clinical application of the COPD-lung cancer association highlighted by CALABRO et al. [1] is the use of spirometry to better target CT screening for the early detection of lung cancer [1]. Such an approach has already been reported by BECHTEL et al. [13] where including spirometric criteria for CT screening eligibility resulted in a lung cancer pick up rate of $6 \%$, much greater than $\approx 1.0 \%$ reported by CALABRO et al. [1] and others [14] where selection is based on age and smoking history alone. Given the constraints of cost and harms from nontargeted screening with $\mathrm{CT}$, we believe maximising specificity over sensitivity is a much more desirable approach to lung cancer screening. By targeting screening for lung cancer to those smokers with evidence of airway obstruction and/or lung parenchymal damage (emphysema), lung cancer pick up can be substantially improved [13]. We advocate the use of other biomarkers of lung risk, such as gene-based lung cancer risk assessment [15], to further improve pick up rates (specificity) for those undergoing screening for lung cancer. In this regard, we strongly agree with CALABRO et al. [1] in advocating the use of available risk biomarkers (spirometry and genes) to better target lung cancer screening to those smokers at greatest risk.

\section{R. Young and R. Hopkins}

School of Medicine and School of Biological Science, University of Auckland, Auckland, New Zealand.

Correspondence: R. Young, School of Medicine and School of Biological Science, University of Auckland, Auckland, New Zealand. E-mail: robert.young@adhb.govt.nz

Statement of Interest: None declared.

\section{REFERENCES}

1 Calabro E, Randi G, La Vecchia C, et al. Lung function predicts lung cancer risk in smokers: a tool for targeting screening programmes. Eur Respir J 2010; 35: 146-151.

2 Young RP, Hopkins RJ, Christmas T, et al. COPD prevalence is increased in lung cancer independent of age, sex, and smoking history. Eur Respir J 2009; 34: 380-386.

3 de Torres J, Bastarrika G, Wisnivesky JP, et al. Assessing the relationship between lung cancer risk and emphysema detected on low dose CT of the chest. Chest 2007; 132: 1932-1938.

4 Wilson DO, Weissfeld JL, Balkan A, et al. Association of radiographic emphysema and airflow obstruction with lung cancer. Am J Respir Crit Care Med 2008; 178: 738-744.

5 Tockman MS, Anthonisen NR, Wright EC, et al. Airways obstruction and the risk of lung cancer. Ann Intern Med 1987; 106: 512-518.

6 Young RP, Hopkins R, Eaton TE. FEV1: not just a lung function test but a marker of premature death from all causes. Eur Respir J 2007; 30: 616-622. 
7 Burrows B, Knudson RJ, Cline MG, et al. Quantitative relationships between cigarette smoking and ventilatory function. Am Rev Respir Dis 1977; 115: 195-205.

8 Coultas DB, Harris C, Howard CA, et al. Heritability of ventilatory function in smoking and non-smoking New Mexico Hispanics. Am Rev Respir Dis 1991; 144: 770-775.

9 Gottlieb J, Wilk JB, Harmon M, et al. Heritability of longitudinal change in lung function: the Framingham Study. Am J Respir Crit Care Med 2001; 164: 1655-1659.

10 Young RP, Hopkins R, Eaton TE. Pharmacological actions of statins: potential utility in COPD. Eur Respir Rev 2009; 18: 222-232.

11 A catalog of published genome-wide association studies. www. genome.gov/GWAStudies Date last updated: March 17, 2010. Date last accessed: March 24, 2010.
12 Young RP, Hopkins RJ, Hay BJ, et al. Lung cancer gene associated with COPD: triple whammy or possible confounding effect? Eur Respir J 2008; 32: 1158-1164.

13 Bechtel JJ, Kelley WA, Coons TA, et al. Lung cancer detection in patients with airflow obstruction identified in a primary care outpatient practice. Chest 2005; 127: 1140-1145.

14 IELCAP Investigators, Survival of patients with stage 1 lung cancer detected on CT screening. NEJM 2006; 355: 1763-1771.

15 Young RP, Hopkins RJ, Hay BA, et al. A gene based risk score for lung cancer susceptibility in smokers and ex-smokers. Postgrad Med J 2009; 85: 515-524.

\section{Inflammatory myofibroblastic tumour}

\section{To the Editors:}

We read with great interest the article by CALABRESE et al. [1], recently published in the European Resipiratory Journal, in which the authors report two cases of pulmonary inflammatory myofibroblastic tumour with unusual uptake on octreoscan.

CALABRESE et al. [1] report that both the tumours revealed high uptake values (of 25 and 22) on $\left[{ }^{18} \mathrm{~F}\right]$-2-fluoro-deoxy-D-glucose (FDG)-PET/computed tomography (CT). We agree with the findings of these authors as we also have experience of two cases of pulmonary inflammatory myofibroblastic tumour and found similar results on FDG-PET/CT scan (fig. 1) [2, 3]. We believe
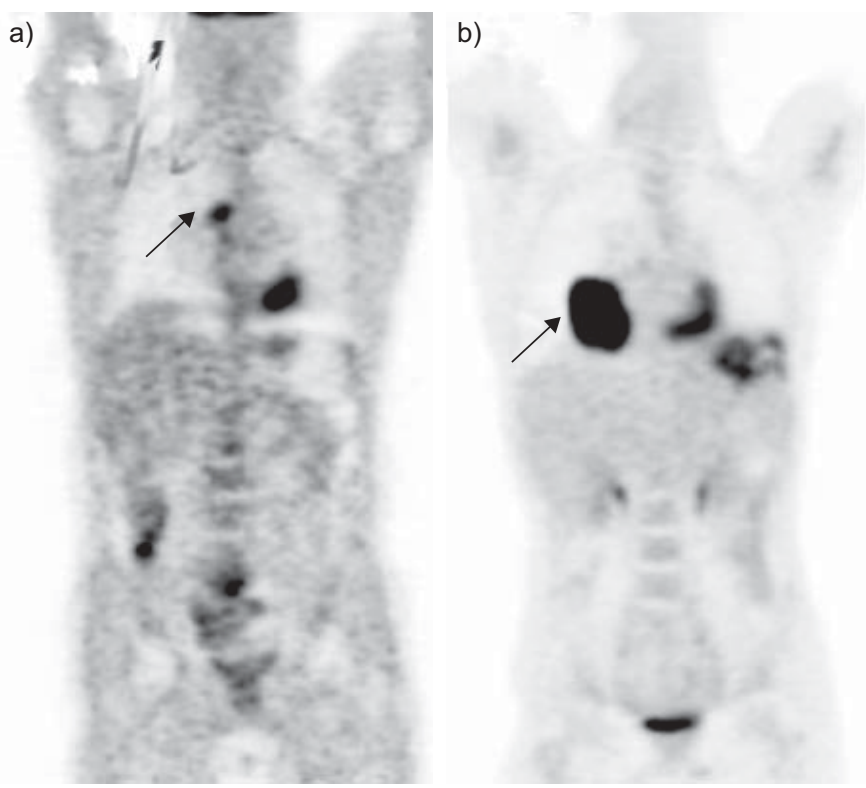

FIGURE 1. $\left[{ }^{18}\right.$ F]-2-fluoro-deoxy-D-glucose (FDG)-PET scans of two cases of pulmonary inflammatory myofibroblastic tumour, demonstrating the tumour as an FDG avid area (arrows). that the reason for such a high uptake in these benign tumours is probably the associated intense inflammation. This leads to increased metabolic activity, which in turn leads to high glucose uptake resulting in high uptake on FDG-PET/CT scan.

CALABRESE et al. [1] report these tumours to be positive on an octreoscan. In our own studies, we performed ${ }^{68} \mathrm{Ga}$-DOTATOC PET/CT $\left({ }^{68}\right.$ Gallium-1,4,7,10-Tetraazacyclododecane- $\mathrm{N}^{\mathrm{I}}, \mathrm{N}^{\mathrm{II}}, \mathrm{N}^{\mathrm{III}}$, $\mathrm{N}^{\mathrm{IIII}}$ - tetra acetic acid-(D)-Phel ${ }^{1}-\mathrm{Tyr}^{3}$-octreotide) on the patients, which has the same principle as octreoscan, but found no significant uptake in either patient $[2,3]$. We request that the authors describe what they mean by high/low uptake on octreoscan in semi-quantitative terms of tumour to background ratio. We also request them to mention at what point of time the images were taken ( 4 or $24 \mathrm{~h}$ ).

We would also like to mention that a previous study describes the uptake on octreoscan in these tumours [4]. DE RUITER et al. [4] described an inflammatory pseudotumour in the pterygopalatine fossa that was detected on a somatostatin receptor scintigraphy. They ascribe this uptake to the upregulation of the somatostatin receptors in the inflammatory cells. CALABRESE et al. [1] have not mentioned this report in their manuscript or references.

CALABRESE et al. [1] have documented the presence of somatostatin receptors in the pulmonary inflammatory myofibroblastic tumour using immunohistochemistry. This is an interesting, objective finding as until now, only speculations were made for the positive uptake of these tumours on octreoscan. This may open up new investigative avenues for the functional imaging of these tumours using somatostatin receptor analogues as tracers.

\section{T. Jindal*, A. Kumar* and R. Kumar}

Depts of *Surgical Disciplines. and "Nuclear Medicine, All India Institute of Medical Sciences, New Delhi, India. 